\title{
Driving Instructors are Not Much Better (At Least Sometimes) in Explaining Driving Safety than Ordinary Drivers
}

\author{
Ivars Austers $\mathrm{a}^{*}$ \\ Viesturs Rengǵe \\ Jurǵis Šķiltersc
}

a, b Department of Psychology, University of Latvia, *Corresponding Author Email: austers@lanet.Iv

c Center for Cognitive Sciences and Semantics, University of Latvia

\section{Doi:10.5901/mjss.2015.v6n2s1p416}

\section{Abstract}

The paper reports two studies which were both aimed at exploring differences in the judgement of traffic safety and risks by experts and ordinary drivers. In both studies the group of experts was comprised of driving school instructors. The first study focused on the risk judgements that drivers and experts make on the basis of traffic rule violations in order to predict road accidents. The second study explored driver and expert assessments regarding unwritten driving rules that are related to safe vs. risky driving. The studies demonstrated that experts are only slightly better than ordinary drivers in judging the degree to which traffic accidents are related to violations of certain traffic rules. There were only very slight differences in rating the degree to which an average Latvian driver follows unwritten driving rules. Experts and ordinary drivers did not differ in their assessments on the extent to which particular unwritten traffic rules facilitate traffic safety.

Keywords: Traffic safety and risk judgements; Expert vs. ordinary judgements; Unwritten driving rules; Driving instructors

\section{Introduction}

Drivers very often blame bad roads as well as bad weather for road traffic accidents. However, research shows that the human factor has to be considered as the main cause of traffic accidents (e.g., Underwood, Chapman, Wright, \& Crundall, 1997). The 'human factor' can be understood as including inner psychological states (anger, anxiety), processes (cognitive information processing), personality factors (personality traits, locus of control, aggressiveness, sensation seeking, or optimism), demographic factors (gender, age) and/or attitudes (towards risk, safety, road behavior), finally, categorization and conceptual organization (knowledge structure of experts and novices). Additionally, complex tasks of spatial perception and navigation take place in the context of fast decision making and meaning assignment.

In the present paper our position is that the human factor in driving safety also involves risk judgments by the driver - when driving one has to assess the possibility of an accident caused by the driver him/herself or by the environment or other drivers, in order to be able to take evasive action. Risk, is a concept which we commonly employ in our everyday language as well as in judgment formation and decision-making. People sometimes say that a certain kind of planned behavior is too risky to be undertaken. Or, alternatively, if the predicted risk level is very high, one may decide upon a particular action to reduce that risk - for instance, to insure his or her vehicle. According to the rich tradition of risk judgment studies we know that there are a number of human shortcomings which decrease the ability to predict harmful future events (for a review, see Slovic, 2000). People have problems with risk assessment due to their limited information processing capacities. Risk assessment is situationally constrained, and, thus, involving interaction between subsets of co-determining factors such as emotions, temporal dynamics, and attention, frequently there no clear alternatives from which to chose the correct one (or frequently there is not enough time for decision making) (Robbins \& Aydede, 2009). Further limitations in processing capabilities are related to problems with the perception of randomness (Ross \& Levy, 1958), judgments of correlation and causality (Chapman \& Chapman, 1969), or may rely on the wrong judgment cues, for example, making judgments on the basis of the availability heuristic (Tversky \& Kahneman, 1973). Researchers have also studied traffic risk judgments -- the subjective interpretation of the risk involved in various driving situations (Deery, 1999, Nordfjærn \& Rundmo, 2009). For instance, many studies of driving risk include studies of the relationship of traffic risk judgments to driving behavior (Fuller, 1984, Rundmo \& Iversen, 2004, Summala, 1988, Wilde, 1988).

There are several theoretical approaches which relate the safety of driving to human judgment, namely risk 
assessment. As Summala (Näätänen \& Summala, 1974, Summala, 1988) argues, it is not true that the risk of involvement in a traffic accident depends only on driving skills, or road conditions There is also an important cognitive component involved - a driver strives to keep his/her stress level at a safe level - to control risk by following a zero-risk level.

Drivers' behaviour is apparently characterized by striving to a balance between successful intentional action and cognitive overload: intentional, goal-oriented action is constrained by tendency to minimize cognitive overload and to reduce descriptive complexity of a situation. There is always an interplay between the excitatory and inhibitory processes which determine drivers' behaviour. On the one hand drivers are motivated to achieve certain goals, like saving time by speeding. On the other hand drivers have to monitor hazards, in this way adapting to risk. This is not always achieved since drivers often underestimate risk due to distorted subjective judgments of the distribution of accident probabilities. As Summala (1988) argues, there is a strong component of learning in adaptation to risk: novice drivers obtain driving skills, they learn to control their vehicle in a better and more fluent fashion, yet the downside of the process is that they learn to abandon small stochastic risks. This can be interpreted as a tendency towards reduction of descriptive complexity of a driving situation and can be further characterized as a motivating factor in both non-experienced and experienced drivers; moreover, this tendency is apparently primary in respect to detailed analysis of instructions. Wilde (1988) too, in his theory of risk homeostasis has stated that, while driving, road users follow the level of accident risk to which they feel exposed, at the same time comparing this level to the degree of danger they are ready to accept. Or, to put in a different manner, there is always a trade-off between the perceived benefit of a certain manner of driving and subjective risk. The external features of a driving situation have to be constantly compared to decision-making as well as driving skills. The latter is related to driving experience, of course. A theory of threat avoidance is proposed by Fuller (1984). Namely, that there are two kinds of reactions to threatening stimuli - anticipatory avoidance driving and delayed avoidance driving stimuli. Drivers with the first type of reaction tend to be less involved in accidents. Fuller (1984) also argues that learner drivers would be more expected to make delayed avoidance rather than anticipatory avoidance responses. All the quoted risk theories have traffic safety in their focus. That is, they all not only describe formal or higher cognitive processes of risk judgments - they explicitly relate those cognitions to driving behaviour facilitating or impeding traffic safety. This led us to develop the central question for the present study - are risk judgments dependent on the raters' levels of expertise? Or, stated in a different manner - are those who teach more accurate in risk judgments than those being taught?

Thus, to be able to explore drivers' behavior two kinds of decision making situations with different processing of cognitive representations have to be distinguished: first, situations where decisions are made 'on the fly' integrating primarily procedural world knowledge with the current situation and relying on the active interactional processes between agent and environment. These interactional processes occur without deriving, comparing and selecting possible courses of action but acting according to prior experience in assessing situation and generating, modifying plans using processes of mental simulation (Klein, 1993, Busemeyer, Jessup, \& Dimperio, 2009) ; second, situations with sufficient knowledge resources and decision time to be able to compare different options and decide among them. Only the former kind of processing situations is both critical and characteristic in drivers' behaviour.

When we drive, we largely base our decisions and behavior on our expectations about what others are going to do. In doing this, we are using shared and collaborative knowledge and shared and interactive intentionality and are certainly making metacognitive judgements. Generally, drivers are expected to follow traffic rules to coordinate their interaction when driving. Although all countries have formal traffic laws, the observation of traffic rules is related to legal culture (Yagil, 2005). Thus, drivers' actual behaviour is a result of interaction between legal and cognitive aspect of processing situation. For instance, those who violate traffic rules, will more often also tend to attribute traffic violations to other drivers, and to a higher extent than those who violate rules less frequently (Manstead, Parker, Stradling, Reason, \& Baxter, 1992); expectations about others are self-anchored anticipations which may lead to the development of informal rules of interaction. It has been found that, when passing an intersection, drivers often follow unwritten rules as well as formal traffic rules (Björklund \& Åberg, 2005). There is always a set of rules which are not enforced by the law, but which people consider as standards for guiding their behaviour (Cialdini \& Trost, 1998). These unwritten norms emerge from interaction with others, and sometimes they are not even explicitly declared. Novice drivers have to acquire these informal rules, and they learn them through interaction with other drivers. For example, in a study in Norway (Bjørnskau, 1993), it was found that drivers were taught to dip their headlights at a certain distance before meeting others when driving in the dark. Yet, in real-life settings, the approaching drivers demand the dipping of lights much earlier by flashing their headlights, than at the certain distance taught at driving schools.

The notion of expert is important in the present study. There has been a long history of debates about what constitutes an expert (e.g., Chi, 2006, Ericsson, 2006). The leading tradition is to define experts as persons being skilful and informed in a specific field. The most popular conceptions in this line of reasoning are the ones dealing with individual 
differences in mental capacities, or the qualitatively different representation and organization of knowledge (Ericsson, 2006). Traditionally, the study approach has had a focus on the domains where experts excel. For instance, experts are considered to generate a better option, being better at recognizing meaningful patterns, using different strategies, using less cognitive effort, and sometimes being more opportunistic (Chi, 2006). Yet, another series of studies has focused on the shortcomings and failures displayed by experts. The most studied experts in this series display the following traits: they are domain limited in their abilities, may have a tendency to overlook details, may act in an inflexible manner, and be inaccurate in predictions and judgments (Chi, 2006). Yet, there is another attribute of experts, namely, the social function of experts. As Ericsson (2006) notes, experts are those whose knowledge or skills are considered to be superior to those of others, and who are asked for advice in case of doubt.

There have been studies of expertise in the field of transportation, which also pay attention to automobile driving. In those studies, expertise is defined in terms of the number of years one has been operating a vehicle. Those studies have shown that expert drivers may visually scan the environment in a different manner in comparison to novices, and experienced drivers may have some advantage in detecting potential hazards (Durso \& Dattel, 2006). Or, to be more specific, Duncan and colleagues (Duncan, Wiliams, \& Brown, 1991) in a study of components of driving skills compared three groups of drivers: trained experts, normal drivers, and novices. The study got mixed results; it was not always the case that experience would positively correlate to expertise. For instance, the results showed that with respect to the skills of mirror checking, braking into intersections and the safety margin when following another vehicle, experienced drivers as a group tended to perform fairly badly in comparison to novice drivers who were more similar to expert drivers with respect to these skills.

For the aims of the present study, both experience and the communicative qualities of experts were considered as relevant, as the group of experts was comprised of driving school instructors. Driving instructors have an important social role - they are supposed to transfer the norms of safe driving as well as driving skills. What modern societies need are 'expert systems' or networks of experts, that help a society reduce uncertainty in various domains of life (Mieg, 2006). In this way the impact of expert judgments could become very important. According to Latvian legislation, one has to have a driver's license for at least three years and complete a two month course covering road traffic rules, traffic safety, and teaching methods to be able to become a driving instructor. In addition, driving school instructors, as well as their direct involvement in teaching those wishing to obtain a driver's license, are the ones who are asked to provide public opinions.

The present paper reports two studies, which we designed in order to assess the differences in expert and ordinary drivers' judgments about traffic safety issues. In our studies, we considered driving instructors as the experts. We hypothesized that there should be different patterns in their judgments of driving related matters - in our opinion it would be normatively correct to expect driving school instructors to not only think differently, but also that their judgments should be more about safe driving when compared to those of an 'ordinary' driver. Our first study was aimed at comparing both the traffic risk judgments of traffic experts (driving school instructors) and "ordinary" drivers (those who don't teach others). The second study was focused on studying ordinary and expert judgments about the unwritten rules which drivers follow when interacting with others on the roads. That is, drivers follow a set of unwritten rules when driving, and not all of those rules correspond with the spirit of formal, legal traffic rules. Thus, interaction between legal aspects and driver's world knowledge is not a balanced one. In this study as well, the experts involved were driving school instructors. Our aim was to assess both the judgments of ordinary drivers and experts about a set of the most common unwritten rules, regarding the degree to which they facilitate or impede road safety.

\section{Study 1}

The first study was based on a comparison of the judgments of traffic risk factors by drivers (represented by two groups, the ones who have not violated traffic rules, and those who have done so to a substantial degree) and traffic experts. All the risk factors represented the most frequent accident causes according to the official records of traffic accidents (Road Traffic Safety Directorate, 2010). The violators' group was included in the sample as we assumed that risky driving (rule violations) may be related to lower risk judgments. We compared the judgments of all three groups of study respondents by focusing our attention on a factor being related to road safety: the seriousness of violations of certain traffic rules (operationalized as the rankings of accidents as a consequence of those violations). 


\subsection{Method}

\subsubsection{Participants and Procedure}

A total of 183 participants took part in the study. Participants represented one of the three groups: non-violating drivers ( $\mathrm{n}$ $=78$, mean age $=36.59$ (range from 18 to 89 ); $\mathrm{SD}=15.49,51.28 \%$ were females); violating drivers (drivers, who have earned eight penalty points ${ }^{1}, n=74$, mean age $=33.82$ (range from 18 to 64 ); $S D=11.58$, of them $5.41 \%$ were females). Experts $(n=32)$ were represented by instructors from driving schools, with their age range being from 23 to $72,(M=42.78$; $\mathrm{SD}=14.83) ; 12.50 \%$ were females. In the case of non-violating drivers, the data was collected from the Road Traffic Safety Directorate, a Latvian state agency which issues drivers licenses and registration documents for vehicles. During the procedure for obtaining the above-mentioned documents, applicants have to wait some 15 to 20 minutes while their documents are processed. The participants were approached by a research assistant while they were waiting. Experts were contacted at driving schools - driving school instructors filled in a questionnaire either individually or in small group settings. The third group, violating drivers, were contacted at the courses provided for drivers who have earned eight penalty points for breaking traffic laws. The violators were approached by a research assistant and asked to participate in the study. Participation in the study was on an unpaid voluntary basis.

\subsubsection{Measures}

All participants received a questionnaire containing questions on their opinion of the seriousness of violations of certain traffic rules (frequency of accidents as a consequence of those violations). Participants were asked to rank in order (to assign ranks from the highest to the lowest) ten items to the extent to which they may be causes of traffic accidents. The lists were constructed on the basis of police protocols, which are written up by police officers after inspecting the location and conditions at an accident site, as well as including violations of traffic rules related to the accident. Following the annual statistics issued by Latvian Road Traffic Safety Directorate based on police records, we chose the most frequently mentioned traffic rule violations in relation to accidents (Road Traffic Safety Directorate, 2008).

\subsection{Results and discussion}

The main findings of Study 1 are presented in Table 1. First we used the Kruskal-Wallis test to determine the differences between the judgments of the three groups.

Table 1. Ascribed ranks of traffic rule violations as leading to accidents

\begin{tabular}{lccc}
\hline & $\begin{array}{c}\text { Rank for drivers -non-violators } \\
(\mathrm{n}=78)\end{array}$ & $\begin{array}{c}\text { Rank for drivers- violators } \\
(\mathrm{n}=74)\end{array}$ & $\begin{array}{c}\text { Rank for experts } \\
(\mathrm{n}=32)\end{array}$ \\
\hline Violation of traffic rules at crossings & 5.26 & 4.62 & 4.29 \\
Tailing & 3.74 & 4.12 & 3.81 \\
Violation of traffic signs & 5.18 & 5.27 & 5.81 \\
Violation of lane changing rules & 5.47 & 5.77 & 5.13 \\
Speeding* & 2.21 & $3.11^{\mathrm{a}}$ & $1.77^{\mathrm{a}}$ \\
Violation of driving in reverse rules* & 8.95 & $8.58^{\mathrm{a}}$ & $9.58^{\mathrm{a}}$ \\
Overtaking & 3.97 & 3.89 & 4.68 \\
Violation of traffic lights & 5.71 & 5.68 & 5.58 \\
Violation of pedestrian crossing rules & 6.45 & 6.58 & 5.97 \\
Violation of U-turn rules* & 8.06 & $7.38^{\mathrm{a}}$ & $8.52^{\mathrm{a}}$ \\
\hline
\end{tabular}

${ }^{*}$ mean ratings by the groups are significantly different (Kruskall-Wallis test, $p<.05$ ).

a means in each row that are significantly different (Mann-Whitney test with Bonferroni correction, $p<.05$ ).

There were significant differences between mean ascribed ranks of the following traffic rule violations as leading to accidents: speeding $(X 2(2, N=183)=8.32, p<.05)$; violations of driving in reverse rules $(X 2(2, N=183)=6.30, p<.05)$;

${ }^{1}$ After earning eight penalty points drivers receive an invitation to participate in a course on safe driving. After the course two penalty points are canceled, which may be important from a drivers' perspective, as after earning twelve points one has to pass an exam or lose their driving license. If the courses are attended, two penalty points are extinguished 
and violations of U-turn rules $(X 2(2, N=183)=7.14, p<.05)$. We also tested the differences in ratings between groups for cases where the Kruskal-Wallis test was significant by comparing them pair-wise, by using the Mann-Whitney test with a Bonferroni correction (see Table 1). The test did not show any differences in ratings by violators and non-violators, yet, there were differences between experts and violators. Namely, violators rated speeding as being a less important violation leading to accidents, while violations of driving in reverse and U-turn rules were estimated as being more important.

\section{Study 2}

The focus of this study was twofold - first, we wanted to assess the opinions of both drivers and experts/instructors about the extent to which certain informal rules are followed among drivers in Latvia. Second, we also wanted to ask representatives of both groups their opinions about the extent to which informal driving rules promote road traffic safety.

\subsection{Method}

\subsubsection{Participants and Procedure}

A total of 248 participants took part in the study. Two hundred and sixteen were ordinary drivers and thirty-two were experts. The mean age of the drivers was 31.77 (range 18 to 62) and $37 \%$ of the drivers were females. The mean age of the experts was 46.78 (range 21 to 73) and 31\% were females. Drivers were approached in a similar manner to that in Study 1 - they were approached by a research assistant while they were waiting at the Road Traffic Safety Directorate. As in Study 1, the group of experts was also formed by driving school instructors, who were approached at driving schools and who completed the questionnaire individually.

\subsubsection{Measures}

Firstly, during the preparatory study we generated a set of unwritten rules which are typically followed by drivers in Latvia. To do so, three focus group interviews, with a total of 17 participants, were conducted in order to get a broader representation of drivers' knowledge and attitudes towards unwritten rules. One focus group consisted solely of men, one solely of women, and the third was mixed with respect to gender. After analyzing the results of the focus group interviews, a set of seven rules was formulated (see Table 2). During the main stage of the study respondents (both drivers and experts) had to answer to what extent "an average driver in Latvia" engaged in behaviours corresponding to the unwritten rules (answers on a seven-point scale ranging from "never" to "almost always when there is an opportunity"). After that, a second set of questions was asked about the degree to which the following unwritten rules facilitate or impede traffic safety (ratings on a bipolar seven-point scale ranging from "substantially impedes traffic safety on roads" $(-3)$ to "substantially facilitates traffic safety on roads" (+3).

\subsection{Results and discussion}

The main findings are presented in Table 2 and Table 3. A t-test analysis was done to compare the ratings made by representatives of both groups. As one can see from the results, there were some differences in judgments regarding the extent to which people follow a given set of unwritten rules. In general, experts were slightly inclined to have a more negative view about driving behaviour in Latvia. Namely, they reported that "the average driver in Latvia" signals to others about a police post more often, that they thank each other less frequently, and that they are less inclined to change lanes to give way to others, than the respondents in the driver group reported. On the other hand, there were no significant differences in judging the extent to which the unwritten traffic rules impede road safety. However, the pattern of the judgments was interesting on its own - besides the uniformity of views, it was reported that signalling another driver about a police post is something that slightly facilitates road safety (group means were 0.54 and 0.65 , different from 0 , $p<.05$ ). In addition, representatives of both groups assumed that it was generally not good to drive $10 \mathrm{~km} / \mathrm{h}$ faster than the speed limit (group means were -0.22 and -0.42 , different from $0, p<.05$ ). Yet, basically the same behaviour in a different setting - speeding in order to follow the flow - was considered to be a behaviour generally having a positive impact on traffic safety (group means were 0.88 and 0.74 , different from $0, p<.05$ ). 
Table 2. Judgments of the degree to which an "average driver in Latvia" follows these unwritten traffic rules

\begin{tabular}{|c|c|c|c|c|}
\hline & Driv & & Expe & \\
\hline & Mean & SD & Mean & SD \\
\hline Warn other drivers about a police post by signalling with lights. & $4.03^{*}$ & 1.91 & $4.77^{\star}$ & 1.87 \\
\hline Yield to those who have been waiting long on a road of lesser significance. & 4.43 & 1.99 & 4.00 & 1.57 \\
\hline Thank other drivers by blinking emergency lights or waving. & $5.86^{*}$ & 1.55 & $5.29^{*}$ & 1.42 \\
\hline Drive $10 \mathrm{~km} / \mathrm{h}$ faster than the allowed speed. & 5.48 & 1.83 & 5.35 & 1.52 \\
\hline $\begin{array}{l}\text { Change lanes to provide driving space for those entering the road from the road of lesser } \\
\text { significance, when it is possible. }\end{array}$ & $5.10^{*}$ & 1.70 & $4.32^{*}$ & 1.19 \\
\hline Signal to drivers who have forgotten to switch on headlights. & 4.83 & 1.94 & 4.65 & 1.74 \\
\hline Speed in order not to slow the traffic flow. & 5.12 & 1.99 & 4.77 & 1.56 \\
\hline
\end{tabular}

*t-test significant, $p<.05$, computed t values range from 2.04 to 3.12

Ratings were made on a seven-point scale from 1 to 7.

Table 3. Ratings of the extent to which unwritten traffic rules facilitate traffic safety

\begin{tabular}{lcccc}
\hline & \multicolumn{2}{c}{ Drivers } & \multicolumn{2}{c}{ Experts } \\
\cline { 2 - 4 } & Mean & SD & Mean & SD \\
\hline Warn other drivers about a police post by signalling with lights. & 0.54 & 1.59 & 0.65 & 1.58 \\
Yield to those who have been waiting long on a road of lesser significance. & 1.04 & 1.27 & 0.84 & 1.32 \\
Thank other drivers by blinking emergency lights or waving. & 1.15 & 1.34 & 0.74 & 1.12 \\
Drive $10 \mathrm{~km} / \mathrm{h}$ faster than the allowed speed. & -0.22 & 1.25 & -0.42 & 1.41 \\
Change lanes to provide driving space for those entering the road from the road of lesser & 1.26 & 1.21 & 1.06 & 1.29 \\
significance, when it is possible. & 1.94 & 1.10 & 1.90 & 1.08 \\
Signal to drivers who have forgotten to switch on headlights. & 0.88 & 1.45 & 0.74 & 1.69 \\
Speed in order not to slow the traffic flow. & &
\end{tabular}

Ratings were made on the scale from -3 (impends) to +3 (facilitates).

\section{General Discussion}

The primary aim of the studies presented in this paper was to examine the judgments of driving experts (in the present case - driving school instructors) in comparison to 'ordinary' drivers. In particular, we studied the judgments about the relationship of actual accidents to violations of driving rules. In addition, the beliefs about the degree to which specific unwritten driving rules are generally assumed, and their relationship to road traffic security were studied. In effect, the results are in favour of the opinion that the degree of accuracy of expert judgments is often overestimated. It seems that in many cases the perception of experts as trustworthy is due to their social status and professional role rather than the actual quality of their conclusions.

Our studies have clearly demonstrated that experts are only slightly different than ordinary drivers in judging the extent to which traffic accidents are related to violations of certain traffic rules. Similarly, there were only minor differences in the ratings of the degree to which an average Latvian driver is involved in following unwritten driving rules. The latter finding may not be surprising, since both experts and ordinary drivers may base their judgments on similar observations of actual road driving in Latvia. However, of greater surprise is the fact that both groups did not differ in their judgments of the extent to which particular unwritten traffic rules facilitate or impede traffic safety.

On the other hand, we cannot make too generalized a conclusion based on our findings, since we had a limited number of experts participating in our study. To some extent it may be explained by the process of risk judgments given by Rundmo and colleagues (e.g., Rundmo \& Moen, 2006). They assume that people are keener to make risk estimates based on the severity of consequences of an event than on an assessment of the possibility of an event. Along with this tendency to pay a substantial amount of attention to the severity, at the expense of the possibility, it also seems that participants in their judgments of traffic rule violations leading to accidents are under the influence of the availability heuristic (Tversky, \& Kahneman, 1973), as they overestimate violations like speeding or overtaking, as often described in the media and as fought against by advertising campaigns, as leading to accidents. Meanwhile, a group of violations which are less debated publicly, like violations of traffic rules at crossings, are underestimated. To explain further, speeding is the leading traffic rule violation according to the published data (Road Traffic Safety Directorate, 2010b), yet not the most dangerous. Generally, this biased tendency of judgments based on the information available in one's memory was present both for the experts and the lay drivers. Alternatively, it is possible that drivers are more concerned 
with a subjectively perceived risk level, which may be done either in assessing zero-risk level (Summala, 1988), risk homeostasis (Wilde, 1988), or threat avoidance (Fuller, 1984). In all those explanations of risk judgments drivers are portrayed as being more concerned with the immediate road and traffic conditions and caring less about the frequency and possibility of accidents.

It is known that expert drivers may visually scan the environment in a different manner in comparison to novices, and in a similar manner experienced drivers may have some advantage in detecting potential hazards (Durso \& Dattel, 2006). We acknowledge that in the present study we did not measure the degree of experience of the experts, like their absolute driving mileage or years of driving. Because of this, an alternative explanation for our results may exist, namely, that the lack of differences between groups may be attributed to similar experience. This explanation has to be ruled out in future studies. We also acknowledge that the present study does not solve the complications arising from the wellknown fact that minor crashes are very much underreported. In addition, single vehicle collisions may be underreported in comparison to two or more vehicle collisions. Yet, we believe that this general problem reflects both sides of the reality judgments by drivers as well as statistics of accidents.

Another slightly generalized explanation of the current results says that there are fewer differences between the categorization of experts and novices in the situation where self-evaluation is referring to action (cp. Tanaka \& Taylor, 1991, Chi, Feltovich, \& Glaser, 1981, Murphy, 2002). Apparently the differences in knowledge structure has less impact in self-assessment, although a more careful study of underlying categories in case of novices and experts is needed where e.g. objects identification should be tested. Another related factor that might play a role in current results is an observation that the impact of underlying categories on risk judgments is less determining (cp. Murphy, 2002). Perhaps experts possess more complex and more abstract domain-knowledge but self-evaluation and resistance to categorization effects in risk judgments reduce the differences between novices and experts. A question outside the scope of the current study is how exactly expertise impacts knowledge organization.

The results of the present studies also have important implications from the applied perspective - it seems that driving school instructors may be overly involved in teaching driving skills and not paying enough attention to teaching their students the skills related to traffic risk estimation. In general, we have gained data which point to the importance of attitudes towards driving that perhaps are no less important than the driving skills themselves.

\section{Acknowledgments}

This study was financed by the Latvian Council of Science Grant 06.2007. We thank the Latvian Road Traffic Safety Directorate for supplying us with statistical data and Sandra Sebre for her comments.

\section{References}

Björklund, G. M., \& Åberg, L. (2005). Driver behaviour in intersections: Formal and informal traffic rules. Transportation Research Part F, Traffic psychology and behaviour, 8, 239-253.

Bjørnskau, T., (1993). Spillteori, trafikk og ulykker: En teori om interaksjon i trafikken [Game theory, road traffic, and accidents: A theory of road user interaction]. Oslo: Transportøkonomisk Institutt, TØI-rapport 287/1994.

Busemeyer, J. R., Jessup, R. K., \& Dimperio, E. (2009). The Dynamic Interactions between Situations and Decisions. In P.Robbins, \& M. Aydede (Eds.) The Cambridge handbook of situated cognition (pp. 307-321). Cambridge: Cambridge University Press.

Chapman, L. J., \& Chapman, J. P. (1969). Illusory correlation as an obstacle to the use of valid psychodiagnostic signs. Journal of Abnormal Psychology, 74, 271-280.

Cialdini, R. B., \& Trost, M. R. (1998). Social influence: Social norms, conformity, and compliance. In D. T. Gilbert, S. T. Fiske, \& G. Lindzey (Eds.), The handbook of social psychology (4th ed., Vol. 2, pp. 151-192). New York: McGraw-Hill.

Chi, M.T.H. (2006). Methods to assess the representations of experts' and novices' knowledge . In K.A. Ericsson, N. Charness, P. Feltovich, \& R. R. Hoffman (Eds.), Cambridge handbook of expertise and expert performance. (pp. 167-184). Cambridge: Cambridge University Press.

Chi, M. T., Feltovich, P. J., \& Glaser, R. (1981). Categorization and representation of physics problems by experts and novices. Cognitive science,5(2), 121-152.

Deery, H. A. (1999). Hazard and risk perception among young novice drivers. Journal of Safety Research, 30, 225-236.

Duncan, J., Williams, P., \& Brown, W. (1991). Components of driving skill: experience does not mean expertise. Ergonomics, 34, 919937.

Durso, F. T., \& Dattel, A. R. (2006). Expertise in transportation. In A. Ericcson, N. Charness, P. Feltovich, \& R. R. Hoffman, Handbook of expertise and expert performance (pp. 1084-1134). Cambridge: Cambridge University Press.

Ericsson, K. A. (2006). The influence of experience and deliberate practice on the development of superior expert performance. In K. A. Ericsson, N. Charness, P. Feltovich, \& R. R. Hoffman (Eds.). Cambridge handbook of expertise and expert performance (pp. 685- 
706). Cambridge: Cambridge University Press.

Fuller, R. (1984). A conceptualization of driving behaviour as threat avoidance. Ergonomics, 27, 1139-1155.

Klein, G. A. (1993). A recognition-primed decision (RPD) model of rapid decision making. Decision making in action: Models and methods, 5(4), 138-147.

Manstead, A., Parker, D. Stradling, S. G. Reason, J. T., \& Baxter, J. S. (1992). Perceived consensus in estimates of the prevalence of driving errors and violations. Journal of Applied Social Psychology, 22, 509-530.

Mieg, H. A. (2006). Social and sociological factors in the development of expertise. In K. A. Ericsson, N. Charness, P. Feltovich, \& R. R. Hoffman (Eds.). Cambridge handbook of expertise and expert performance (pp. 743-760). Cambridge: Cambridge University Press.

Murphy, G. L. (2002). The big book of concepts. Cambridge, MA: MIT Press.

Näätänen, R., \& Summala, H. (1974). A model for the role of motivational factors in drivers' decision making. Accident Analysis and Prevention, 6, 243-261.

Nordfjærn, T., \& Rundmo, T. (2009). Perception of traffic risk in an industrialised and a developing country. Transportation Research Part F, Traffic psychology and behaviour 12, 91-98.

Road Traffic Safety Directorate (2010). Traffic rule violations. Unpublished raw data.

Road Traffic Safety Directorate (2011). Statistics of road accidents. Extracted from http://www.csdd.lv/?pagelD=1239884427 27.07.2011.

Robbins, P., \& Aydede, M. (Eds.). (2009). The Cambridge handbook of situated cognition. Cambridge: Cambridge University Press.

Ross, B. M., \& Levy, N. (1958). Patterned predictions of chance events by children and adults. Psychological Reports, 4, 87-124.

Rundmo, T., \& Iversen, H. (2004). Risk perception and driving behaviour among adolescents in two Norwegian counties before and after a traffic safety campaign. Safety Science, 42, 1-21.

Rundmo, T., \& Moen, B.E. (2006). Risk perception and demand for risk mitigation among experts, politicians and lay people in Norway. Journal of Risk Research, 9(6), 623-640.

Slovic, P. (2000). The perception of risk. London: Earthscan.

Summala, H. (1988). Risk control is not risk adjustment: the zero-risk theory of driver behaviour and its implications. Ergonomics, 31, $491-506$.

Tanaka, J. W., \& Taylor, M. (1991). Object categories and expertise: Is the basic level in the eye of the beholder?. Cognitive psychology, 23(3), 457-482.

Tversky, A., \& Kahneman, D. (1973). Availability: A heuristic for judging frequency and probability. Cognitive Psychology, 5, 207-232.

Underwood, G., Chapman, P. Wright, S., \& Crundall, D. (1997). Estimating accident liability. In T. Rothengatter \& E. Carbonell (Eds.), Traffic and transport psychology (pp. 247-258). Oxford: Elsevier.

Wilde, G. J. S. (1988). Risk homeostasis theory and traffic accidents: propositions, deductions and discussion of dissension in recent reactions. Ergonomics, 31, $441-468$.

Yagil, D. (2005). Drivers and traffic laws: A review of psychological theories and empirical research. In G. Underwood (Ed.), Traffic \& transportation psychology. Theory and application (pp. 487-503). Amsterdam: Elsevier 